Canad. Math. Bull. Vol. 20 (3), 1977

\title{
TRIVECTORS IN A SPACE OF SEVEN DIMENSIONS
}

\author{
R. WESTWICK
}

In their paper [1], Buseman and Glassco state that $N(C, 7,3)=5$ has been claimed but questioned. Schouten in [2] provides a classification of the orbits of $\Lambda^{3} V$ under the action of the group of automorphisms of $\Lambda^{3} V$ induced by automorphisms of $V$ when $\operatorname{dim} V=7$. The only possible candidate in the list for a trivector with irreducible length 5 is (VII 5) and the observation that

$$
\overline{162}+\overline{243}+\overline{351}+\overline{174}+\overline{675}=\overline{1(6+4)(2-7)}+\overline{135}+\overline{24(3+1)}+\overline{67(5+1)}
$$

shows that its length is at most 4 , and since type (VII $4 \beta$ ) has 4 blades, $N(C, 7,3)=4$.

Some condition on the ground field of $V$ is required to get the classification given by Schouten. In $\Lambda^{3} V$ where $\operatorname{dim} V=6$ and the ground field is the reals there is an extra orbit with

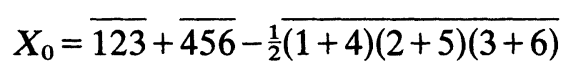

as a representative. That $X_{0}$ is not in the orbits listed follows from the fact that $x \wedge X_{0}$ is never decomposable for non-zero $x \in V$, (this is easily checked using the pliicker relations). For the types listed when the rank of $X$ is at most 6 it is clear that there always is a non-zero $x$ for which $x \wedge X$ is decomposable.

\section{REFERENCES}

1. H. Buseman and D. E. Glassco, Irreducible Sums of Simple Multivectors, Pac. J. of Math., vol. 49, no. 1, 1973, (13-32).

2. J. A. Schouten, Klassifizierung der alternierenden Gröszen Dritten Grades in 7 Dimensionen. Cir. Mat. di Palermo, vol. 55, 1931, (137-156).

DEPT. OF MATH.

UNIVERSITY OF B.C.

VANCOUVER, B.C.

Canada

Received by the editors June 28, 1976. 